\title{
Charge e enunciados-respostas: a contrapalavra rompendo e construindo sentidos
}

\author{
Fabíola Maciel Saldão \\ Universidade Federal de São Paulo (UNIFESP), Guarulhos, São Paulo, Brasil \\ fabiola.saldao@gmail.com
}

DOI: http://dx.doi.org/10.21165/el.v46i3.1532

\begin{abstract}
Resumo
Encontrada na mídia, geralmente em jornais e redes sociais, a charge é um gênero que promove um complexo diálogo com os aspectos presentes na sociedade de forma bastante política, irônica e crítica. Tais elementos contribuem para que a charge seja um relevante objeto de análise para os estudos dialógicos discursivos, em especial, para compreender como os sentidos são construídos no discurso. Este trabalho, sinalizando tal rica configuração e tendo como base teórica os escritos de Bakthin e o Círculo, visa responder aos seguintes questionamentos: como ocorre a construção dialógica de sentidos considerando a produção e recepção dos discursos, em charges com alta repercussão (proporcionaram número alto de comentários e manifestações de leitores)? Como diferentes vozes sociais se engendram e refletem sentidos no discurso? A fim de dar resposta a estes questionamentos, foi selecionado como corpus para a presente discussão uma charge do cartunista João Montanaro do jornal Folha de São Paulo e também foram selecionados dois comentários de leitores sobre a referida charge dispostos na página do cartunista na rede social Facebook. Os conceitos sobre dialogismo e construção de sentidos estão presentes em todo trabalho, além das contribuições filosóficas sobre a concepção de atos éticos responsáveis e responsivos, os estudos sobre a concepção do enunciado como unidade da comunicação discursiva e algumas reflexões sobre os elementos que compõem o gênero charge. A partir das análises realizadas é percebível a diversidade de sentidos construídos (as rupturas e os elos constituídos) dentro da cadeia comunicativa discursiva a partir dos diferentes aspectos valorados pelos leitores em relação ao teor crítico da charge.
\end{abstract}

Palavras-chave: charge; dialogismo; ato ético; sentidos; discurso.

\section{Cartoons and set out-answers: the one word against the other breaking and building meanings}

\begin{abstract}
Found in the media, usually in newspapers and social networks, the cartoon is a genre that promotes a complex dialogue with aspects that permeate society in a highly political, ironic and critical form. These elements contribute so that cartoon be an important object of analysis for dialogic-discursive studies, in particular to understand how meanings are built in the speech. This article, by signaling such rich arrangement and with the theoretical basis of Bakhtin's writings and the Circle, aims to answer the following questions: How does occur the dialogic construction of meanings considering the production and acceptance of speeches in cartoons with high impact (which generated many comments and statements from readers)? How different social voices engender and reflect meanings in speech? In order to answer these questions, it was selected as the corpus for the present discussion, a cartoon by the cartoonist João Montanaro in Folha de São Paulo newspaper and two comments from readers on that cartoon were also selected, which were available in the cartoonist's page in the social network Facebook. The concepts on dialogism and construction of meanings permeate all work beyond the philosophical contributions on the design of responsible and responsive ethical acts, studies on the design of the utterance as a unit
\end{abstract}


of discursive communication and some reflections on the elements of the cartoon genre. From the performed analysis, we can realize the diversity of meanings constructed (the breaks and made links) within the discursive communication chain from the different aspects valued by readers regarding the critical content of the cartoon.

Keywords: charge; dialogism; ethical act; senses; speech.

\section{Introdução}

Há muito tempo tenho tido alguns questionamentos sobre as possibilidades de estudar a charge como instrumento de crítica e recepção de notícias veiculadas nos mais diferentes meios de comunicação. Na sala de aula, como professora, percebo o quanto é complexo desenvolver atividades atreladas a este enunciado multimodal, pois, há a dificuldade de os alunos traçarem mecanismos de compreensão. Por inúmeras vezes, senti insegurança na abordagem de ensino que utilizava e no tratamento que dava às charges em sala de aula, em uma perspectiva mais significativa, fugindo dos processos de leitura que valorizavam a superfície textual e a decodificação dos elementos explícitos.

Atualmente, iniciei meus estudos sobre os pressupostos teóricos de Bakthin e seu Círculo. As leituras e a compreensão das ideias do pensador russo fizeram com que eu me debruçasse nas charges publicadas no presente ano e realizasse uma leitura um pouco mais aprofundada e criteriosa.

A afinidade emergiu porque, depois de analisar algumas teorias, percebi que os conceitos bakthinianos constituem um instrumento teórico-reflexivo para compreender como ocorre o processo de construção de sentido em discursos. Além desse viés, pude perceber que existe meu viés de pesquisadora, o qual enxerga a linguagem como um processo dialógico, que somos constituídos no mundo de uma forma dialógica com o outro, que somos discursos em movimento eterno de respostas e que ainda há ditos que estão por vir.

A partir dos estudos das obras Marxismo e Filosofia da Linguagem, Estética da Criação Verbal e Por uma filosofia do ato responsável, pude aprofundar os estudos acerca da teoria bakhtiniana e compreender que essa teoria proporciona a problematização da produção, circulação e recepção do discurso nos mais variados campos de atuação humana. Além disso, questões como a unicidade e a eventicidade do Ser, a relação eu/outro, a axiologia inerente ao ato humano, conceitos elaborados pelo pensador russo, auxiliam na compreensão e no concebimento da linguagem como um fenômeno vivo que se nutre do contínuo desenvolvimento social.

Os questionamentos maiores com que eu me deparava, ao realizar as leituras das charges nos meios de comunicação eram: como ocorria este processo de construção dialógica na charge e quais eram os elementos que estavam em jogo neste processo. A partir daí, as ideias do Círculo de Bakthin entraram em cena, oportunizando a discussão sobre tais questionamentos. Dessa forma, pude dar tratamento a dois pontos que me eram frutíferos: a análise dialógica do discurso e o gênero discursivo charge.

No presente trabalho, além dos elementos acima arrolados que me trouxeram inquietações e questionamentos, também considerei as características fortes presentes no gênero charge, pois articulei com a premissa da teoria bakhtiniana de que a linguagem deve ser analisada e estudada em conexão com o social. Desse modo é dada grande importância às relações de interação social. 
A partir destas observações teóricas, a charge, como todo enunciado vivo e concreto, não pode ser desvinculada de sua situação de produção. Talvez seja este o fator que particularize a charge, além do fato de recuperar valorativamente, muitas vezes de modo velado, temas da atualidade que, se não identificados pelo leitor, trazem prejuízos para o entendimento dos sentidos produzidos. Sobretudo, no que diz respeito ao projeto enunciativo de estabelecer uma crítica, nem sempre aparente, sobre determinado tema que esteja em evidência na sociedade.

Todo este processo de recuperação de temas da atualidade e o processo de construção de sentido traz o princípio dialógico configurado por Bakthin e seu Círculo como base, pois é o que dá origem à construção de sentidos. Na recepção da charge, acontece um movimento tenso de diálogo entre vozes, uma vez que, no seio de sua construção, estão ancorados discursos os quais a originaram e com os quais ela dialoga por meio da crítica.

Assim, pretendo analisar como ocorre a construção dialógica de sentidos, considerando a produção e a circulação dos discursos, em charges com alta repercussão, ou seja, charges que tiveram número alto de comentários e manifestações dos leitores nos meios de comunicação, publicadas nas redes sociais, e também observar como diferentes vozes sociais se engendram e refletem sentidos no discurso.

Delimitei como recorte para as análises charges de alta repercussão e comentários e as manifestações destas charges, todos veiculados no jornal Folha de São Paulo (versão impressa e online) do ano de 2015, que fizessem referência a fatos divulgados pela mídia brasileira também neste ano. Do montante de quatro charges encontradas, selecionei para análise uma charge produzida pelo cartunista João Montanaro e dois comentários e manifestações (que chamo, no decorrer da análise de enunciados-respostas) de leitores da referida charge, sendo dispostos na página do cartunista na rede social Facebook.

Este artigo será constituído da parte introdutória, fundamentação teórica, que apresenta a articulação entre os preceitos bakthinianos: ato ético responsível, dialogismo, signo ideológico e produção de sentidos, estudados para a fundamentação da análise discursiva da charge, e a parte que trará reflexões sobre a leitura/recepção da charge e de dois enunciados-resposta edificados por razão da charge em questão.

\section{A perspectiva dialógica da linguagem e a charge}

Ao longo da história, inúmeros foram os estudos sobre a linguagem e sobre a importante relação construída entre linguagem e sociedade. $\mathrm{Na}$ área de estudos linguísticos, as contribuições denotam o quanto podemos enxergar uma sociedade ou uma comunidade a partir dos aspectos desencadeados pela linguagem.

Para Câmara Jr. (2011), o interesse pelo estudo da linguagem dá-se à medida que a sociedade vai-se desenvolvendo e tornando-se mais complexa. Para o autor, existem fatores importantes que alicerçaram as investigações envolvendo a linguagem a partir deste viés: sociedade e desenvolvimento.

Os tipos de estudo envolvendo a linguagem são estabelecidos desde o surgimento das gramáticas de caráter normativo, apresentando propostas de atividades mecânicas, visando à diferença entre o certo e errado originário das diferenciações entre classes sociais até a percepção acerca da função social da linguística. 
Muitas teorias emergiram ao longo do caminho, cada uma com seu objeto de estudo definido e todas com consequências na forma como enxergamos nosso objeto de trabalho. Assim, teorias enunciativas e discursivas surgiram, sob diferentes perspectivas, e passaram a tecer reflexões, tendo como base o entendimento de que a língua e seu emprego não podem ser analisadas isoladamente.

Neste sentido, destacam-se os estudos de Bakhtin e seu Círculo. Em Marxismo e filosofia da linguagem (2009, p. 71-92), Bakhtin/Volochínov levanta questionamentos acerca de qual seria o objeto da filosofia da linguagem, qual sua natureza concreta e qual metodologia utilizar para estudá-lo.

Os pensadores russos diferenciam-se das orientações do pensamento filosóficolinguístico do século $\mathrm{XX}$, as quais foram denominadas de subjetivismo idealista e objetivismo abstrato. Ambas lidam com uma concepção monológica da linguagem, centrados em uma ótica associada a uma subjetividade individual.

Bakhtin/Volochínov diferencia-se dessas duas correntes e, em seu livro de 1929, entende que a língua, por ser dinâmica, só pode ter sua concretização na enunciação, materialização da interação verbal social entre sujeitos ativos:

[...] na prática viva da língua, a consciência linguística do locutor e do receptor nada tem a ver com um sistema abstrato de formas normativas, mas apenas com a linguagem no sentido de conjunto dos contextos possíveis de uso de cada forma particular. Para o falante nativo, a palavra não se apresenta como um item de dicionário, mas como parte das mais diversas enunciações dos locutores $\mathrm{A}, \mathrm{B}$ ou $\mathrm{C}$ de sua comunidade e das múltiplas enunciações de sua própria prática linguística (BAKTHIN, 2009, p. 98).

O enunciado como resposta aos enunciados anteriores e as relações dialógicas que o mantém como organismo vivo, constituído de sentidos, se entrelaça com alguns preceitos filosóficos articulados por Bakthin na obra Para uma filosofia do ato responsável (2010). Na respectiva obra, Bakhtin nos apresenta uma reflexão sobre o agir humano no mundo concreto, social e histórico, que está suscetível a mudanças, não só no aspecto material ou físico, mas na forma como os sujeitos enxergam este mundo e o traduzem por meio da linguagem, agindo em situações específicas e protagonizando um evento único.

O pensador nos traz o conceito de ato, que para ele sempre está atrelado ao sentido plural, a um agir plural. Por este viés, o ato é visto como referência ao agir humano como um todo, enquanto falar em atos retoma o aspecto particular, concreto. Todos os atos têm em comum, então, os seguintes elementos: um sujeito que age, um lugar em que esse sujeito age e um momento no qual ele age. Os sujeitos agem em situações concretas e a partir de práticas sociais e históricas.

$\mathrm{O}$ autor traz a problematização da questão ética da responsabilidade e da responsividade em relação aos outros sujeitos, ao considerar as ações realizadas pelos sujeitos. $\mathrm{Na}$ afirmação de que "não há álibi na existência", ele traz a exigência da responsabilidade pelos atos e pelas relações com o outro. Assim sendo, ser "responsível", na visão bakthiniana, é criar uma posição perante o dizer, como alguém que assume responsabilidade naquilo que fala/faz, visto que todo ato constitui-se num evento único, irrepetível, pois nunca ocorrerá novamente da mesma forma. 
Havendo então dois centros de valor - o meu e o do outro - em torno dos quais a ação responsível se organiza, devem eles interpenetrar-se: "a relação arquitetônica entre um e outro deve permanecer sob o ponto de vista espaço-temporal e axiológico de forma que o ponto de vista do 'eu' não prevaleça" (BAKTHIN, 2010, p. 41). Essa posição figura ainda na primeira parte do escrito filosófico:

$\mathrm{Eu}$, o exclusivo e único eu, não posso em nenhum momento ser indiferente (parar de participar) à minha vida "sem álibi" e de ocorrência obrigatoriamente única; devo ter o meu dever. Em relação a tudo, independente do que possa ser e em quaisquer circunstâncias que me possam ser dadas, devo agir desde meu próprio e único lugar, mesmo que eu o faça interiormente. Minha singularidade, uma vez que não coincidente com coisa alguma que não seja eu, sempre torna possível minha única e insubstituível ação própria quanto a tudo que não seja eu mesmo. Quer dizer, desde meu lugar único no Ser, simplesmente vejo e conheço o outro, não o esqueço, já que, para mim, ele existe isto é algo que apenas eu posso fazer por ele em um dado momento com todo o meu Ser: esta é a ação que torna seu ser mais completo, a ação absolutamente vantajosa e nova, e que é possível apenas para mim. Essa ação produtiva e única é precisamente o que constitui o momento do dever em si. O dever torna-se possível pela primeira vez onde existe um reconhecimento da existência singular de uma pessoa a partir do interior mesmo dessa pessoa; onde esse fato se torna um centro de responsabilidade, onde eu aceito a responsabilidade por minha própria singularidade, por meu próprio ser (BAKHTIN, 2010, p. 41-42).

Neste trabalho, realizo uma aproximação entre os dois preceitos: enunciação e ato ético responsável ou responsível, pois a concepção dialógica da linguagem está no direcionamento para o outro; na condição de ser uma resposta e ser motivador de outras atitudes responsivas. Sendo assim, cada enunciação está direcionada ao outro, à compreensão e resposta desse outro, o que demonstra o seu inacabamento enquanto elo na cadeia da comunicação discursiva. Dessa maneira, a diferença entre o discurso dito monológico e o dialógico está em sua forma externa, haja vista que, segundo Bakthin/Volochínov (2009, p. 250), "sua essência, sua construção semântica e estilística são dialógicas".

Considerando esta perspectiva, os enunciados são carregados de julgamentos de outrem e, por conta disso, a palavra está imersa em um movimento de diálogo com o outro. $\mathrm{O}$ discurso não se refere diretamente à realidade em si, mas está orientado para os discursos que o cercam e, assim sendo, constroem discursivamente os fatos sociais.

Já a palavra é vista pelo Círculo como fator importante da interação eu/outro porque resulta do uso partilhado entre os sujeitos de uma determinada comunidade situada sócio, histórica e culturalmente. A palavra é ideológica por excelência. Ela é "o modo mais puro e sensível de relação social” (BAKHTIN/VOLOCHÍNOV, 2009, p. 36). A palavra é tomada como neutra por seu potencial de assumir diferentes papéis, diferentes ideologias, conforme cada campo em que é empregada (BAKTHIN/VOLOCHÍNOV, 2009, p. 37). E por esse motivo ela pode preencher-se de diferentes avaliações, constituindo múltiplas construções de sentido.

Nas análises propostas no presente trabalho, as questões ideológicas serão observadas a partir do valor ideológico em que se apresenta a palavra a partir das charges, pois advém da sociedade, das relações interindividuais. 
Bakthin explica que o processo de construção ideológica ocorre como o desenvolvimento de um determinado valor particular por grupos pertencentes à sociedade ao longo da história. A partir desta valoração, nasce a ideologia. Nessa perspectiva, está a máxima: "não pode entrar no domínio da ideologia, tomar forma e assim, deitar raízes senão aquilo que adquiriu um valor social" (BAKHTIN/VOLOCHÍNOV, 2009, p. 45).

É o chamado horizonte social que permite a existência do signo ideológico. Objetos das diferentes áreas da realidade podem entrar no horizonte social de um determinado grupo, a partir do momento em que forem compartilhados entre indivíduos que se encontrem socialmente e historicamente situados. A partir deste registro, pode-se dar origem a um signo ideológico; só nessas condições é que há índice de valor. É importante ressaltar que o signo ideológico origina-se a partir do meio social porque é o embate de vozes que o constitui. No cerne do signo, índices de valor distintos estão em conflito. Isso o torna plurivalente; dinâmico, capaz de trazer uma ressignificação (BAKHTIN/VOLOCHÍNOV, 2009, p. 47).

$\mathrm{Na}$ enunciação, na materialização das interações verbais, a partir da relação dialógica entre os elementos (verbais e visuais), os signos ideológicos são refratados e refletidos. Só ocorre a enunciação se acontecer de fato a interação entre indivíduos situados em um universo cultural e que realizam uma manifestação dentro de um projeto enunciativo.

As vozes sociais dão valência aos signos quando são utilizadas em diferentes esferas de comunicação. Para Brait e Melo (2007, p. 67), "um enunciado implica muito mais do que aquilo que está incluído dentro dos fatores estritamente linguísticos, o que, vale dizer, solicita um olhar para outros elementos que o constituem".

Todos estes aspectos acima arrolados e desenvolvidos na perspectiva bakthiniana auxiliam na compreensão da composição e no estilo dos enunciados concretos. O que pretendo neste trabalho é tecer algumas reflexões pontuais a partir da análise de um enunciado chárgico (charge) e os enunciados-respostas que permeiam tal enunciado, considerando a charge como elemento central da cadeia comunicativa discursiva e que possibilita, em uma relação intrínseca, a construção de elos que discursivamente orientam a emersão de outros enunciados, em movimentos ideologicamente fragmentados.

\section{A Charge, Montanaro e o Uber - confronto entre vozes}

No dia 24 de julho de 2015, no Rio de Janeiro, ocorreu uma manifestação de taxistas organizada pelo sindicato da categoria contra a atuação do serviço Uber no município. As mídias impressa e televisiva divulgaram notícias sobre a manifestação e acompanharam os posicionamentos diversos entre governantes municipais, representantes sindicais, estudiosos, usuários dos dois serviços e defensores do Uber, sobre a atuação do serviço no país. A divergência entre taxistas e a empresa Uber produziu inúmeros enunciados que circularam em diferentes esferas discursivas, com opiniões distintas de diversos enunciadores.

No dia 25 de julho de 2015, foi publicada no jornal Folha de São Paulo a charge abaixo (Figura 1) de autoria do cartunista João Montanaro, no caderno "Tendências e Debates". A charge inspirada na respectiva manifestação provocou diversas respostas, entre as quais, destacamos dois comentários de leitores publicados na página do cartunista na rede social Facebook. O cartunista alimenta diariamente a página da rede social com 
as charges publicadas no jornal Folha de São Paulo e possui número significativo de leitores que apreciam a charge e interagem com o cartunista a respeito dos aspectos estéticos e implícitos das charges publicadas.

A charge em questão foi a mais comentada na página do cartunista no ano e a que teve maior número de comentários negativos e conflitantes.

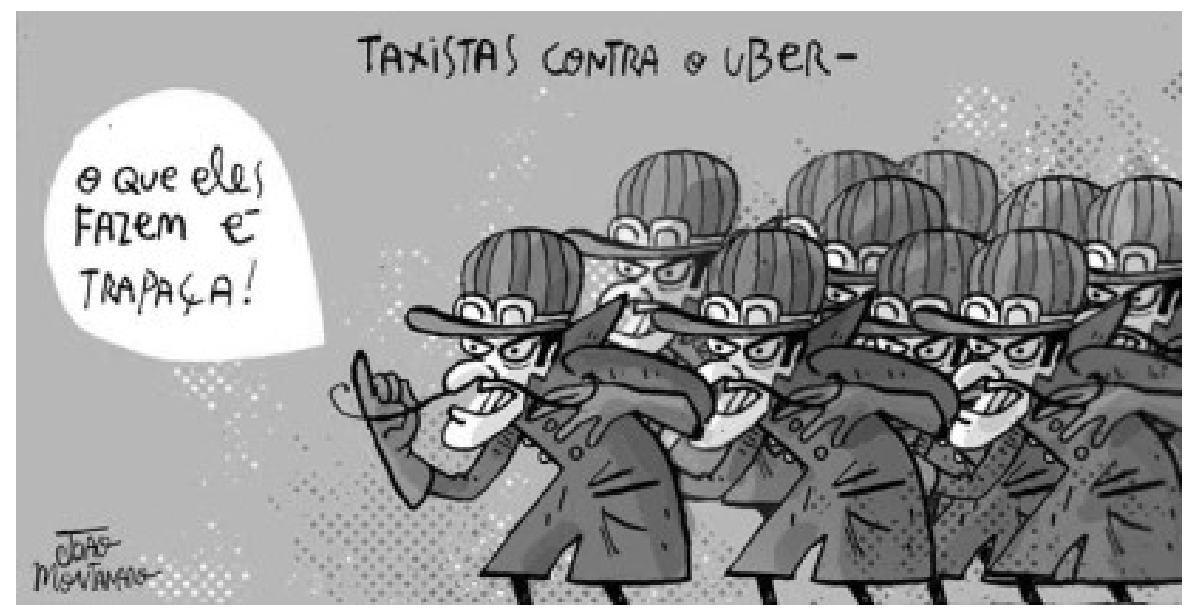

Figura 1. 25 de julho de 2015 - Folha de São Paulo - versão online e impressa

Segundo Andrade (2014), a charge pode ser caracterizada como uma subdivisão da caricatura enquanto gênero artístico, enquanto linguagem gráfica que é construída como possibilidade de caracterizar, ressaltar fisionomia, gestos e comportamentos. Ela pode trazer em sua composição uma série de recursos gráficos que colaboram para a construção do seu projeto enunciativo de crítica; a caricatura é apenas um destes.

Ao realizarmos a leitura de uma charge, percebemos a inclinação crítica desse tipo de enunciado, bem como, sua ligação com os discursos que circulam na sociedade em que estamos inseridos. Nas palavras de Romualdo (2000), a charge é "um texto visual humorístico que critica uma personagem, fato ou acontecimento político específico". Por ter como foco uma realidade específica, ela se atrela mais ao momento, à situação imediata, tendo, portanto, uma limitação temporal. Para o autor, a caricatura e os elementos da linguagem visual (traços, formas, cores, fisionomia dos personagens) estão imbricados na charge porque, muitas vezes, o cartunista usa como recurso de produção de sentido o elemento caricatural.

Observamos que essa charge mostra a imagem do personagem Dick Vigarista em destaque no primeiro plano e em tons sombreados sua reprodução ao fundo. Dick Vigarista é um personagem fictício de um desenho animado em série americano chamado Corrida Maluca e ele é caracterizado como um vilão que planeja incansavelmente como ganhar uma corrida (A corrida maluca). Para vencer a corrida, faz uso de uma série de estratégias que buscam "trapacear" os concorrentes, porém não há sucesso em seus planos e ele nunca consegue ganhar a prova.

Além da imagem do personagem, há a presença de um componente linguístico no balão: “O que eles fazem é trapaça!” e também há a presença da legenda na charge "Taxistas contra o Uber". 
À parte os sentidos que depreendemos dessa charge, e que serão analisados a seguir, destaca-se a presença do fato social: as manifestações dos taxistas contra a atuação do serviço Uber no Brasil.

É importante ressaltar que, a partir do discurso verbo-visual que se apresenta na charge, é observada uma crítica ao posicionamento dos taxistas cariocas sobre a atuação do serviço Uber. $\mathrm{O}$ tema da charge dialoga com as inúmeras notícias sobre as iniciativas de regulamentação do serviço do Uber nas principais capitais brasileiras e sobre os argumentos utilizados pelos taxistas. Eles alegam que o Uber é um concorrente desleal, em virtude de não necessitar de alvarás e licenças especiais emitidas pelas prefeituras das cidades, exigidas para a oferta de serviço de táxi, e criticam também o fato de o Uber oferecer um serviço diferenciado com recursos como oferta de bebidas e balas.

Além do diálogo com as notícias veiculadas sobre a oferta do serviço Uber, há a presença de um diálogo marcante com as inúmeras notícias sobre a atuação de taxistas no Brasil e, em especial, com a recepção de turistas estrangeiros e a prestação de serviços a usuários que desconhecem o roteiro de destino. É destacada, como exemplo, a notícia veiculada no site InfoMoney com o título "Os 10 golpes mais comuns praticados contra turistas", a qual salienta a questão da má postura dos profissionais taxistas, que superfaturam corridas e realizam trajetos mais longos. Há uma forte intertextualidade explícita com o personagem Dick Vigarista, usado pelo cartunista para convidar o interlocutor a uma espécie de jogo dialógico com efeitos de sentido que permitem a construção de uma narrativa espirituosa.

Para a leitura da charge em questão, é importante o conhecimento de sua situação de produção, pois é necessário conhecer os fatos sociais que originaram o enunciado para compreender as vozes que estão dialogando em seu interior e, assim, entender como os sentidos estão sendo construídos.

É importante ressaltar que, neste caso, a charge traz a crítica quanto ao posicionamento construído pelos taxistas de alegarem que o serviço Uber é um serviço desleal e que atua sem a devida regularização. Porém, há o confronto ideológico forte que sinaliza também a postura da classe de taxistas com relação aos serviços que oferta, em especial, aos turistas em visita ao país.

A charge em questão teve alto índice de rejeição, segundo a página do cartunista na rede social Facebook. Na página, podem-se ler 26 comentários dispostos no post da charge. De acordo com os comentários publicados, a charge traz um posicionamento do cartunista a favor do serviço Uber no Brasil. Podemos ver:

(01) "Preconceito é preconceito! Contra homossexuais, negros, religiões... E agora contra taxistas!! Parabéns". Comentário 1.

Podemos ler também:

(02) "Vc quer audiência, mas eu não vou te dar. Crie sem difamar, ou vc não consegue chamar atenção sem polemizar." Comentário 2.

$\mathrm{Na}$ leitura desses interlocutores, a charge dá voz ao preconceito à classe profissional e a generalização da atuação desonesta de todos os taxistas ao fazer uso da imagem do personagem Dick Vigarista. Nessa perspectiva, suas apreciações demonstram uma atitude responsiva negativa na recepção da charge. A palavra "preconceito" e o verbo 
“difamar", presentes nos comentários, levam-nos a compreender que, para os leitores, o tema foi construído na tensão entre vozes sociais que anunciam que os taxistas estão sofrendo preconceito como outras classes (comentário 1: "Preconceito é preconceito! Contra homossexuais, negros, religiões... E agora contra taxistas!! Parabéns") e vozes sociais que dizem que há uma difamação da classe de taxistas em virtude da criação de uma polêmica para que o cartunista fique conhecido ou tenha seu trabalho de produção da charge reconhecido (comentário 2: "Crie sem difamar, ou vc não consegue chamar atenção sem polemizar."). O conflito, pois, dá-se porque há, ainda, o entendimento de que a charge possa reafirmar a postura de "trapaça" e de enganação dos taxistas e de que o cartunista está polemizando a questão a partir da criação da charge, porém de uma forma discriminatória e difamatória.

Para o leitor que não tem conhecimento do projeto enunciativo da charge e dos elementos que a constituem bem como o elemento da crítica de um fato gerador que tenha acontecido, pode-se dizer que os signos ideológicos da charge principal foram apreendidos como reflexo das falas dos personagens. Isto quer dizer que não foi alcançada a refração dos signos, no sentido de se perceber a criticidade que o gênero charge supõe.

Sendo assim, pode-se ressaltar que ocorreu uma espécie de compreensão focada na significação linguística das palavras que constituem o discurso verbal da charge e ganham valorização nos elementos visuais (o personagem Dick Vigarista), mas não houve apreensão do tema do enunciado. A compreensão do tema, pois, depende da observação dos enunciados verbo-visuais, engendrados à situação de produção, tendo em vista $\mathrm{o}$ gênero charge e sua vocação à crítica.

Conforme nos orienta Bakhtin, na leitura, entendida como compreensão, devemos assumir uma atitude responsiva ativa frente ao que lemos e produzimos diferentes encadeamentos discursivos a partir dos valores deflagrados no ato de leitura da charge. No caso da relação entre a charge e os discursos-resposta observados, percebemos que não foram mobilizados os mesmos encadeamentos discursivos na produção da charge e na sua recepção, o que acabou estabelecendo um confronto ideológico de opiniões.

Não se trata de o leitor ter o conhecimento prévio, mas, nesse processo de compreensão da charge lida, a mesma manifestação visual assume diferentes acabamentos semióticos - constituem signos ideológicos diferentes.

Percebe-se uma aproximação estrita ao objeto fonte de apreciação, no caso o personagem Dick Vigarista, em detrimento da condição maior da situação de enunciação em que a charge é produzida. Nesse processo de leitura, o leitor não se afasta de sua esfera de atuação para colocar-se no lugar do outro e reconhecer outras interpretações e reflexões.

O que é percebido é que os leitores, motivados por seu horizonte social que dá valoração à proibição do serviço Uber no Brasil, vincularam a cena retratada na charge aos aspectos negativos contra os taxistas. É como se as pessoas não conseguissem se afastar de suas convicções e formações e julgassem a charge somente desse lugar axiológico, construindo uma afirmação de que o cartunista estabeleceu um posicionamento arbitrário, ofensivo, atrelando questões de uma forma antiética.

O sentido criado no enunciado da charge é uma crítica aos posicionamentos dos profissionais taxistas sobre o serviço Uber no país. A classe profissional aponta como serviço desonesto e cheio de trapaças para a conquista de clientes, possibilitando assim 
uma concorrência desleal. Porém, a classe profissional de taxistas no país é vista sendo composta por profissionais que atuam com desonestidade na oferta de serviços e assim há o uso do personagem Dick Vigarista para instrumentalizar a crítica e salientar as questões que envolvem desonestidade, corrupção e má fé na atuação dos taxistas.

Há o destaque dado à mensagem verbal "O que eles fazem é trapaça!”, um signo simbólico por excelência, porém, compreendemos que a relação entre mensagem não verbal e verbal forma, nas charges, um todo harmonioso com um único fim: trazer a crítica com tom de humor. Para Bakhtin/Volochínov (2009), todas as manifestações da criação ideológica, todos os signos não-verbais, banham-se no discurso e não podem ser nem totalmente isoladas nem totalmente separadas dele.

\section{Considerações finais}

Os estudos desenvolvidos no presente trabalho foram embasados, principalmente, na compreensão de língua/linguagem em uso, como a entende o Círculo de Bakhtin, e também se ancorou nas noções de gêneros discursivos, enunciado, palavra, acento de valor e vozes sociais.

A partir do diálogo com os autores do Círculo, podemos analisar que a divergência em relação à construção de sentido acontece porque, no ato de analisar os elementos verbo-visuais que constituem o discurso chárgico, o leitor somente efetiva a análise a partir de seu ponto de vista. Não há um afastamento do leitor para com o projeto de dizer da charge.

A partir da leitura e análise do enunciado chárgico, o leitor pode perceber, conforme nos diz Bakhtin (2011, p. 385), que "o sentido é potencialmente infinito, mas pode atualizar-se somente em contato com outro sentido" [...].

Os discursos que possivelmente deram origem à charge, bem como os enunciados que surtiram como uma contrapalavra foram lidos e analisados para compreender como se construiu o sentido fruto da interação social entre o discurso do cartunista, tema (objeto do enunciado/isto de que se fala) e leitor (interlocutor).

As análises permitiram entender como essas noções podem ser percebidas em enunciados de cunho crítico e considero que o estudo realizado não é conclusivo, por isso, outras interpretações dos enunciados presentes podem ser estudadas, porém, mesmo que isso ocorra, já não será mais este enunciado que virá à tona e sim outro, pois o enunciado não se repete: é impossível remontar todos os elementos que possibilitaram que tal enunciado surgisse. As repetições podem responder a este enunciado sem que isso descarte o enunciado primeiro.

\section{REFERÊNCIAS}

ANDRADE, A. C. de. A charge: análise do processo enunciativo-discursivo numa perspectiva dialógica. 2014. 329 f. Tese (Doutorado em Letras) - Programa de Pósgraduação em Letras, Universidade Federal de Pernambuco, Recife, 2014.

BAKHTIN, M. Apontamentos de 1970-1971. In: Estética da Criação Verbal (1979). Tradução de Paulo Bezerra. 6. ed. São Paulo: Martins Fontes, 2011. 
. Gêneros do Discurso (1952-1953). In: . Estética da Criação Verbal.

Tradução de Paulo Bezerra. 6. ed. São Paulo: Martins Fontes, 2011 [1979].

. Para uma filosofia do ato responsável (1920-1924). Tradução de Valdemir Miotello e Carlos Alberto Faraco. São Carlos: Pedro e João Editores, 2010.

BAKHTIN, M./VOLOCHÍNOV, V. N. Marxismo e filosofia da linguagem. Tradução de Michel Laud e Yara Frateschi. São Paulo: Hucitec, 2009.

BRAIT, B.; MELO R. Enunciado/enunciado concreto/enunciação. In: BRAIT, B. (Org.). Bakhtin: conceitos-chave. São Paulo: Contexto, 2007. p. 61-78.

CÂMARA JR, J. Mattoso. História da Linguística. 7. ed. Petrópolis: Vozes, 2011.

ROMUALDO, E. Charge jornalística: intertextualidade e polifonia - Um estudo de charges da Folha de S. Paulo. Maringá: Eduem, 2000.

Recebido em: 13/08/2016

Aprovado em: 19/12/2016 